\title{
Secuestro pulmonar en un lactante
}

\author{
FERNANDO BRACHO M. ${ }^{1}$, GUSTAVO PIZARRO T. ${ }^{2}$, JOSÉ A. SEPÚLVEDA C. ${ }^{3}$ \\ 1. Pediatra. Jefe Servicio Pediatría, Hospital Dr. Augusto Essmann de Puerto Natales. \\ 2. Pediatra. Unidad de Respirología Infantil, Hospital Regional Punta Arenas Dr. Lautaro Navarro A. \\ 3. Cirujano Infantil. Jefe Servicio de Cirugía Infantil, Hospital Dr. Lautaro Navarro A. de Punta Arenas.
}

\begin{abstract}
\section{Bronchopulmonary sequestration in an infant}

Background: Bronchopulmonary sequestration is a rare congenital lung malformation, charactarized by an abnormal segment of bronchopulmonary tisue, irrigated by an anomalous systemic artery. Objective: To report the clinical course of an infant with an intralobar bronchopulmonary sequestration and review the most relevant aspects of this lung malformation. Case-report: A six months-old infant, treated for a pneumonia involving the right lower lobe, with persistence of the consolidation image for more than six weeks. Because of a computed tomography (CT) that showed an image suggesting a bronchopulmonay sequestration, the infant was scheduled for surgery, confirming the presence of the intralobar type of the malformation, which was removed without incidents. Conclusion: Bronchopulmonary sequestration is a rare congenital lung malformation, but it has to be considered in the presence of recurrent pneumonia or persisting consolidation images.
\end{abstract}

(Keywords: Bronchopulmonary sequestration, lung malformation).

Rev Chil Pediatr 2007; 78 (5): 494-499

\section{RESUMEN}

Introducción: El secuestro pulmonar es una malformación congénita poco frecuente, caracterizada por un segmento anormal de tejido broncopulmonar irrigado por una arteria anómala de origen sistémico. Objetivo: Presentar el caso de un lactante menor con un secuestro pulmonar intralobar y revisar los aspectos más relevantes de este tipo de malformación congénita. Caso Clínico: Lactante menor de 6 meses de edad, tratada por una neumonia del lóbulo inferior izquierdo, con persistencia de la imagen de condensación por más de 6 semanas. Por este motivo se le realizó una Tomografía axial computada (TAC) que mostró una imagen sugerente de secuestro pulmonar, por lo que fue sometida a cirugía, corroborándose la variedad intralobar de esta malformación, la cual fue resecada sin inconvenientes. Conclusiones: El secuestro pulmonar es una malformación congénita poco frecuente, pero que se debe considerar ante la presencia de neumonías recurrentes o imágenes de condensación persistentes.

(Palabras clave: Secuestro pulmonar, malformaciones pulmonares).

Rev Chil Pediatr 2007; 78 (5): 494-499 


\section{Introducción}

El secuestro pulmonar es una malformación congénita poco frecuente, caracterizada por un segmento anormal de tejido pulmonar irrigado por una arteria aberrante de origen sistémico, sin comunicación con el árbol traqueobronquial ${ }^{1}$. Corresponde a la segunda causa de anomalías congénitas a nivel pulmonar, representando un $0,15-6 \%$ de todas las malformaciones en este sistema ${ }^{2}$, ubicándose en el $95 \%$ de los casos en el lóbulo inferior izquierdo ${ }^{1,6}$. Según el revestimiento de pleura visceral que lo contiene, se puede clasificar en las variedades intralobar y extralobar, estando la primera contenida dentro de la pleura visceral del pulmón normal adyacente, mientras que la segunda tiene su propia membrana ${ }^{1,6-8}$. La variedad intralobar corresponde al $75 \%$ de los casos y la extralobar se asocia en un $50 \%$ de los casos a otras malformaciones ${ }^{7,10}$.

El objetivo de esta comunicación es revisar los aspectos más relevantes de los secuestros pulmonares, a través de la exposición de un caso clínico.

\section{Caso clínico}

Lactante menor de 6 meses de edad, sexo femenino, con antecedentes personales de dermatitis atópica y bronquitis obstructiva a los 3 meses de vida, manejada ambulatoriamente con Salbutamol (SBT) y kinesioterapia respiratoria (KTR). Consulta por cuadro de 2 semanas de evolución, caracterizado por tos húmeda, con coriza serosa inicialmente, sin antecedentes de fiebre o dificultad respiratoria, manejada sólo con medidas generales; al examen físico presentaba estigmas de atopia, una frecuencia respiratoria de 30/minuto, sin uso de musculatura respiratoria accesoria y un examen pulmonar con sibilancias espiratorias; se manejó con SBT en aerosol y se citó a control en siete días. Concurre a la semana siguiente, refiriendo que persistía con tos, sin fiebre o dificultad respiratoria; al examen físico se objetivó una frecuencia respiratoria de 35/minuto, sin uso de musculatura respiratoria accesoria y un examen pulmonar con sibilancias espiratorias. Se solici- tó una radiografía de tórax (RxTx) que mostró una condensación en el Lóbulo Inferior Derecho (LID) (figura 1 y 2), iniciándose Claritromicina $15 \mathrm{mg} / \mathrm{kg} /$ día por 14 días y KTR, ante la sospecha de germen atípico por la signología obstructiva, sin historia de fiebre.

Asiste a control en una semana, refiriendo que la tos no había disminuído, sin cambios en el examen pulmonar, por lo que se prescribió Prednisona $1 \mathrm{mg} / \mathrm{kg} /$ día por 5 días, manteniéndose el SBT en aerosol y la KTR. Evaluada nuevamente a los 7 días, se observó disminución de la tos y la signología obstructiva. Por la historia de SBO recurrentes y presentar estigmas de atopia se inició Budesonide 200 ug cada 12 horas, y se solicitó estudio etiológico (Test del Sudor, IgE total, Hemograma y RxTx).

Concurre a control con sus exámenes seis semanas después de realizado el diagnóstico de neumonia, refiriendo que presentaba tos escasa desde hace una semana, sin fiebre ni dificultad respiratoria. En la RxTx persistía la imagen de condensación en el LID, por lo que se derivó a Broncopulmonar. Evaluada al día siguiente por la especialidad referida, fue ciatada a control en 2 semanas con una nueva RxTx para observar la evolución de la imagen, ante el antecedente de neumonía reciente. En el plazo mencionado, la RxTx mostraba una imagen sin cambios significativos con respecto a las placas anteriores (figura 3 y 4), por lo que se solicitó una TAC para descartar una malformación pulmonar. Las imágenes fueron informadas por Radiología como altamente sugerentes de secuestro pulmonar, por la presencia de un vaso anómalo proveniente de la Aorta diafragmática (figuras 5 y 6).

Fue sometida a cirugía a las 24 horas, encontrándose una masa dura en el lóbulo inferior derecho, contenida dentro de la pleura visceral de pulmón adyacente, con una arteria de $7 \mathrm{~mm}$ de diámetro, proveniente de la aorta a nivel diafragmático y un drenaje venoso hacia las venas pulmonares. Estos hallazgos fueron considerados como compatibles con un secuestro intralobar, por lo que se realizó lobectomía clásica, sin incidentes. Evolucionó durante el postoperatorio con una neumonía asociada a ventilación mecánica, que se manejó con terapia antibiótica y oxígeno suplementario, con 


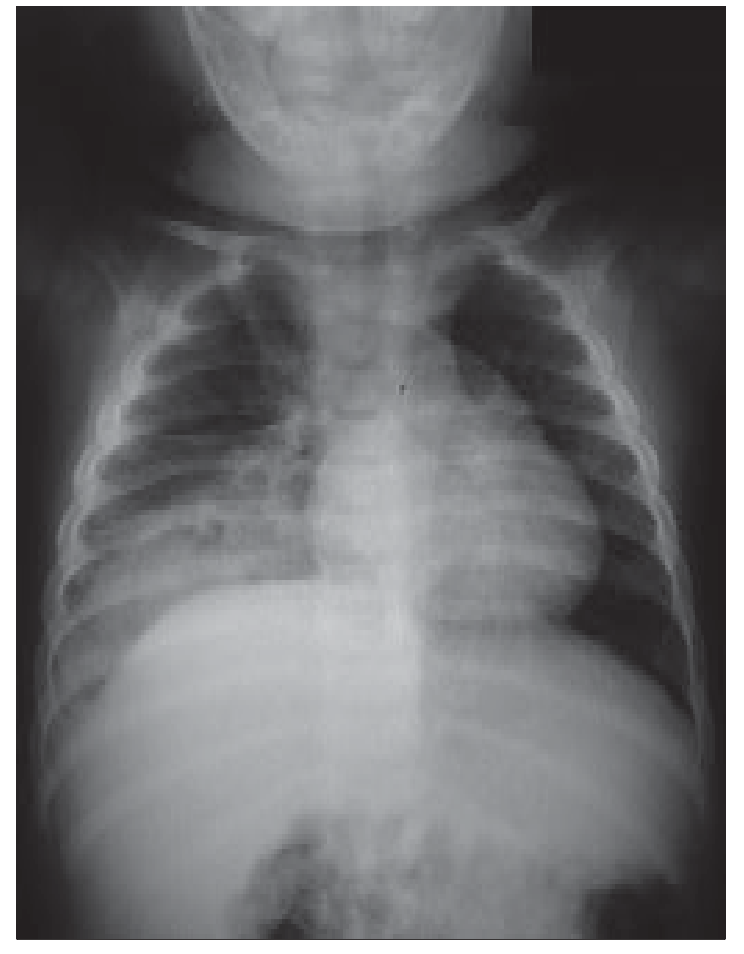

Figuras 1 y 2. Radiografía de Tórax inicial, muestra imagen de

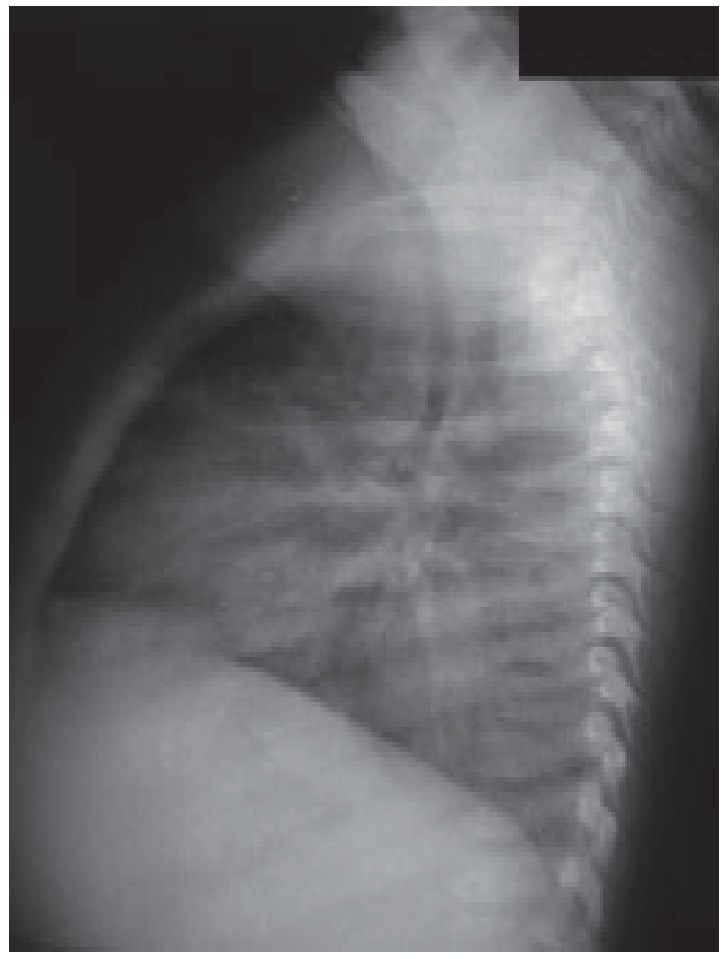

condensación en Lóbulo Inferior Derecho.
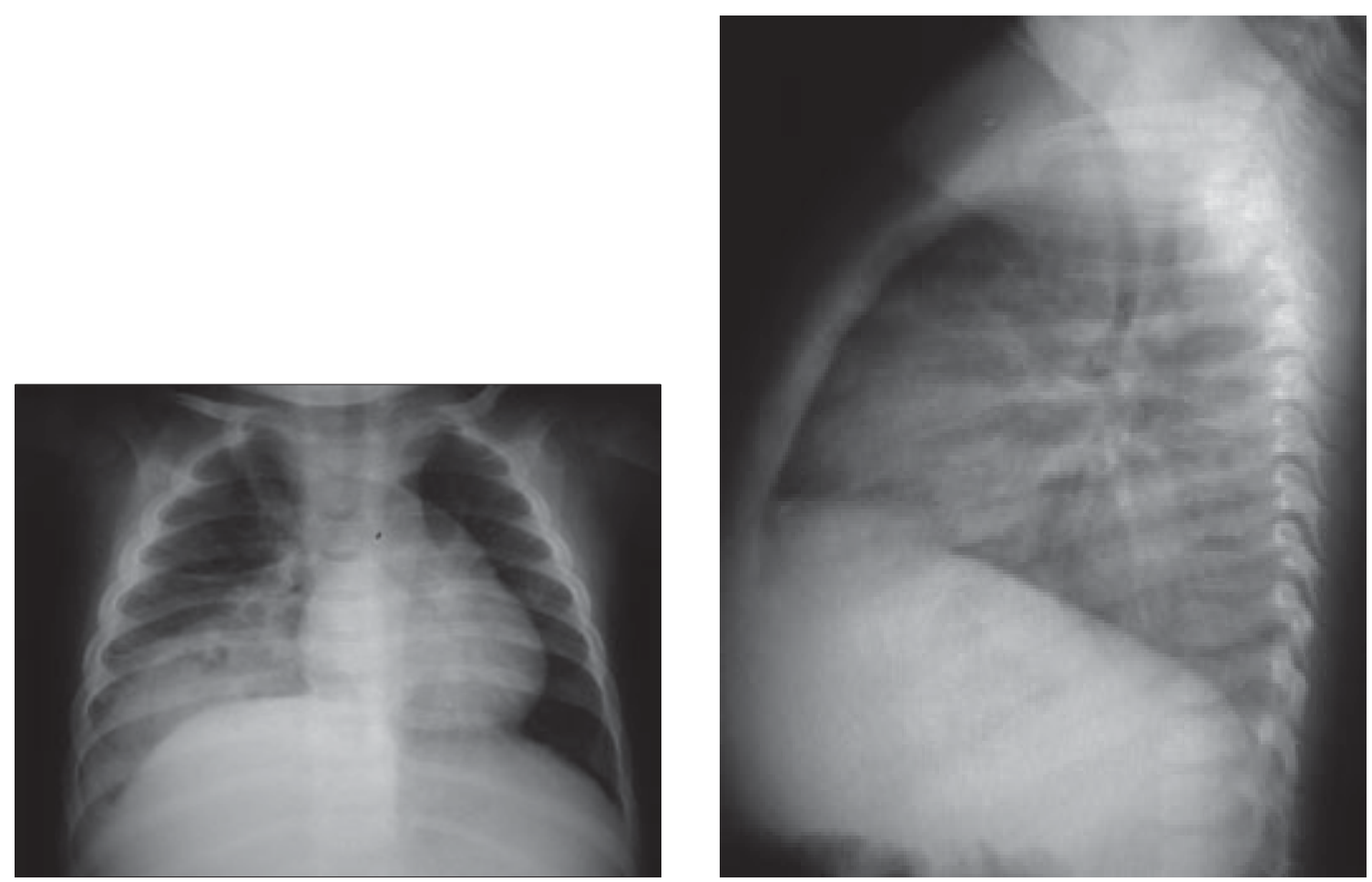

Figuras 3 y 4. Radiografía de Tórax de control, muestra persistencia de la imagen de condensación en Lóbulo Inferior Derecho, con imágenes radiolúcidas en su interior, sospechosas de neumatocele o cavitación. 


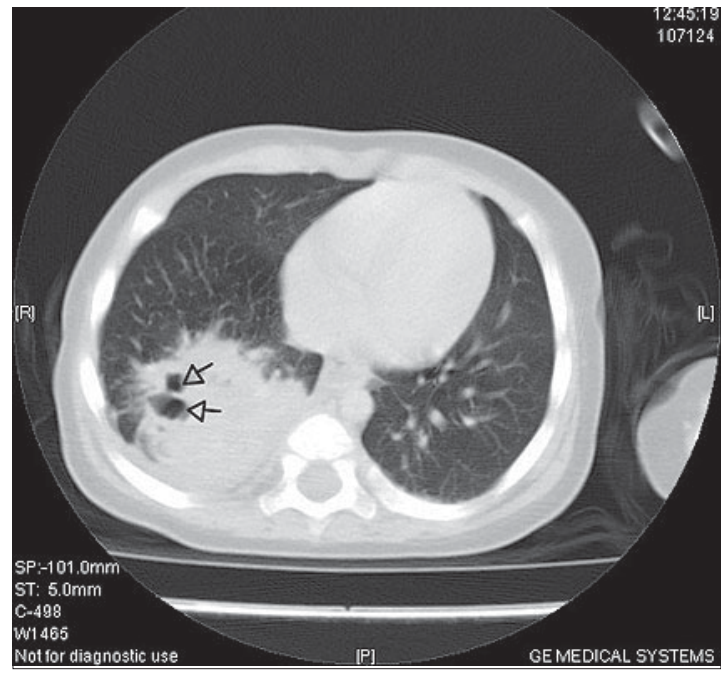

Figura 5. Tomografía axial computada de tórax muestra masa de densidad homogénea en Lóbulo Inferior Derecho, con imágenes quísticas en su periferia (flechas).

buena respuesta, dándose de alta a los 5 días después de su cirugía.

Posteriormente la paciente evolucionó en forma favorable desde el punto de vista quirúrgico, pero persistió con cuadros obstructivos recurrentes. Considerando el antecedente personal de atopia y el estudio que orientaba a esta etiología, se reinició Budesonida inhalatoria, con excelente respuesta, encontrándose actualmente asintomática y en disminución paulatina de la dosis de corticoides inhalatorios.

\section{Discusión}

El término "secuestro pulmonar" fue usado por primera vez por D. Pryce en 1946, para referirse a "una arteria anormal que emerge de la aorta y que irriga a una masa o quiste broncopulmonar, el cual está disociado del árbol bronquial normal"1,7. Múltiples teorías acerca de su etiopatogenia han sido propuestas, siendo la más ampliamente aceptada la que postula que durante la embriogénesis se forma un divertículo pulmonar accesorio, caudal al divertículo normal, que desarrolla una vasculatura independiente, usualmente desde la aorta, mantenién-

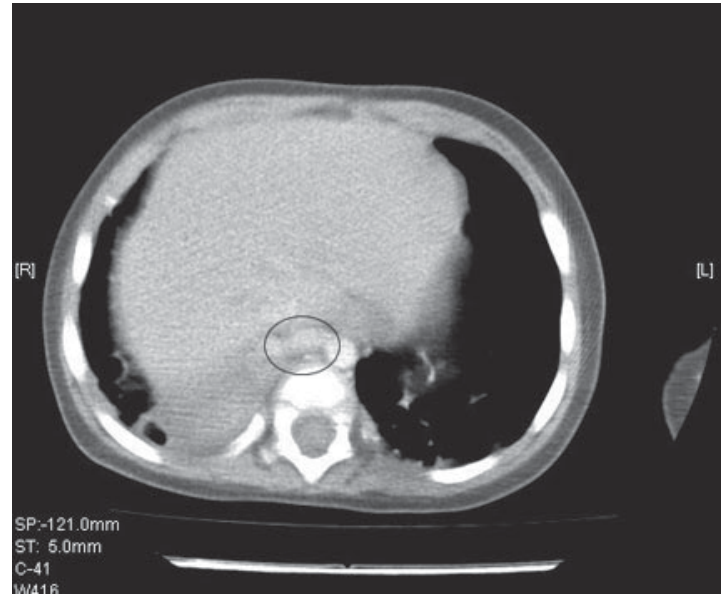

Figura 6. Tomografía axial computada de tórax muestra vaso aberrante emergente de la aorta a nivel de la cúpula diafragmática (imagen encerrada en círculo).

dose aislado del árbol bronquial en desarro$110^{1,2,7}$.

Funcionalmente, no existe una conexión directa entre los secuestros y la vía aérea normal, pero sí a través de los poros de Kohn a nivel alveolar, pudiendo llegar los gérmenes por esta vía. Una vez colonizada la malformación, el desarrollo de la infección es muy probable, debido a la ausencia de un drenaje bronquial normal $^{1,7}$. La irrigación arterial de los secuestros deriva en el $75 \%$ de arterias aberrantes originadas en la aorta descendente, a nivel torácico, con el porcentaje restante repartido entre otras arterias de la región, incluso desde las coronarias o el tronco celíaco. El retorno venoso se canaliza a través de las venas ácigos o cava inferior en la variedad extralobar y a través de las venas pulmonares en la variedad intralobar ${ }^{1,5-7,10}$. En esta última variedad, las arterias tienen una capa muscular delgada, determinando una baja resistencia que permite un flujo sanguíneo elevado, que puede determinar shunt de izquierda a derecha, con repercusiones hemodinámicas ${ }^{7}$. Como resultado de estas características, los secuestros son tumoraciones que ejercen un efecto de masa en el parénquima pulmonar normal adyacente, no participan en el 
intercambio gaseoso, no contribuyen a generar espacio muerto, pero sí pueden desarrollar shunt de izquierda a derecha ${ }^{5,7}$.

La presentación clínica varía según la variedad del secuestro. El tipo extralobar es una patología de diagnóstico eminentemente neonatal, debido a su alta tasa de asociación con otras malformaciones congénitas. En cambio, la variedad intralobar usualmente se descubre en edades posteriores, con una mediana a los 20 años de edad ${ }^{1}$. La gran mayoría de pacientes con este último tipo son asintomáticos, diagnosticándose durante una RxTx de rutina o por síntomas no relacionados. Su sintomatología, cuando se presenta, no es muy específica, produciendo tos productiva, fiebre recurrente, dolor torácico o disnea ${ }^{1,9}$. Al examen físico se puede detectar un área de matidez a la percusión, con disminución del murmullo pulmonar, y crepitaciones finas y sibilancias cuando existe infección ${ }^{5}$.

Los diagnósticos diferenciales se pueden ver en la tabla $1^{1}$.

El estudio de esta patología está orientado a tener la certeza diagnóstica y a determinar la arteria aberrante que irriga la malformación, para facilitar el manejo quirúrgico. La radiogra-

\section{Tabla 1. Diagnóstico diferencial del Secuestro Pulmonar}

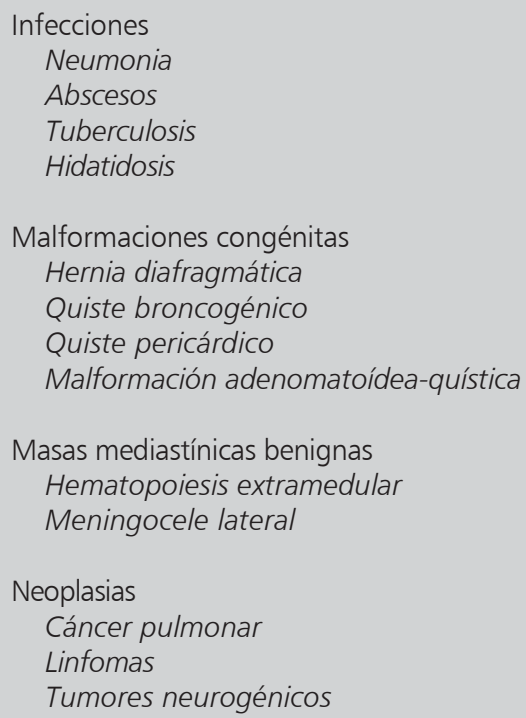

Masas mediastínicas benignas Hematopoiesis extramedular Meningocele lateral

Neoplasias

Cáncer pulmonar

Linfomas

Tumores neurogénicos

fía de tórax habitualmente no es específica y muestra una imagen de condensación con bordes pocos definidos, que puede simular una neumonia o cavitación, o una masa de tejidos blandos con bordes irregularmente definidos ${ }^{3,4,6}$. Como método diagnóstico de elección se prefiere la TAC, la cual muestra una masa, habitualmente en los segmentos medio-basal (S7) o postero-basal (S10) del Lóbulo Inferior Izquierdo, que puede tener imágenes quísticas en su interior $^{1,4,7,8}$. La identificación preoperatoria de la arteria aberrante es muy importante para evitar morbi-mortalidad durante la cirugía, utilizándose Angio-TAC o Angio-RNM como métodos de elección para este propósito, los cuales han logrado evitar el uso de técnicas invasivas como la angiografía ${ }^{1,4-7}$.

El tratamiento de consenso para los secuestros es la remoción quirúrgica, pero el momento de su realización es algo controversial, aunque la tendencia es realizarla ante la confirmación del diagnóstico, debido a reportes de fallecimientos por hemoptisis masivas y para prevenir neumonias recurrentes y otros síntomas relacionados. La cirugía habitualmente implica una lobectomía por toracotomía, aunque también se puede usar la vía toracoscópica. En los casos en que el riesgo quirúrgico es muy grande se puede intentar embolización angiográfica de la arteria aberrante, método que ha probado ser útil como alternativa quirúrgica en niños ${ }^{11,12}$.

En el análisis crítico de este caso clínico, cabe resaltar algunos puntos importantes. El primero es que la presentación de Síndrome Bronquial Obstructivo Recurrente a edades tempranas nos obliga a descartar causas secundarias (Fibrosis Quística, Inmunodeficiencias, Malformaciones de vía aérea o pulmonar, etc.), a pesar de estar sugerido el inicio empírico de corticoides inhalatorios con más de un cuadro obstructivo al mes ${ }^{13}$, sobre todo cuando se tiene el antecedente personal y familiar de atopia ${ }^{14}$, como en el caso particular de esta lactante. En segundo lugar, es discutible la indicación de corticoterapia sistémica en relación a persistencia de sintomatología obstructiva leve, dado los efectos secundarios de dichos fármacos y la ausencia de literatura que avale su uso a edades precoces y en condiciones que no son de emergencia. $\mathrm{Y}$ en tercer lugar, cabe aclarar 
que la premura de su resolución quirúrgica se debió a motivos circunstanciales, al contar en la ocasión con la visita de un cirujano de extensa experiencia en cirugía toráxica, quien en conjunto con el equipo de cirugía pediátrica local decidieron realizar la intervención, con un diagnóstico razonablemente seguro, considerando que las sugerencias de completar el estudio con métodos de imágenes más específicos, retrasaría su resolución quirúrgica.

\section{Conclusiones}

El secuestro pulmonar es una malformación congénita poco frecuente, generalmente asintomática, pero que debe ser tenida en cuenta ante la presencia de neumonías a repetición o imágenes de condensación persistentes, sobre todo si comprometen el lóbulo inferior del pulmón izquierdo.

\section{Referencias}

1.- Cooke CR: Bronchopulmonary Sequestration. Respir Care 2006; 51: 661-4.

2.- Corbett JH, Humphrey GM: Pulmonary sequestration. Paediatr Respir Rev 2004; 5: 59-68.

3.- Zylak CF, Eyler WR, Spizarny DL, et al: Developmental lung anomalies in the adult: radiologicpathologic correlation. Radiographics 2002; 22: 2543.
4.- Bolca N, Topal U, Bayram S: Bronchopulmonary sequestration: Radiologic findings. Eur J Radiol 2004; 52: 185-91.

5.- Green TP, Finder JD: Pulmonary sequestration. En: Behrman: Nelson Textbook of Pediatrics, 17th Ed, Saunders 2004.

6.- Sprigg A: Congenital chest abnormalities. En: Grainger \& Allison's Diagnostic Radiology: A Textbook of Medical Imaging, 4th ed. Churchill Livingstone; 2001.

7.- Shovlin CL, Jackson JE, Hughes JM: Bronchopulmonary Sequestration. En Mason: Murray \& Nadel's Textbook of Respiratory Medicine, 4th ed., Saunders 2005.

8.- Husain AN, Kumar V: The Lung. En Robbins and Cotran: Pathologic Basis of Disease, 7th Ed, Saunders 2005.

9.- Gezer S, Tastepe I, Sirmali M, et al: Pulmonary sequestration: A single-institutional series composed of 27 cases. J Thorac Cardiovasc Surg 2007; 133: 955-9.

10.- Savic B, Birtel FJ, Tholen W, et al: Lung sequestration: report of seven cases and review of 540 published cases. Thorax, Feb 1979; 34: 96-101.

11.- Lee KH, Sung KB, Yoon HK, et al: Transcatheter arterial embolization of pulmonary sequestration in neonates: long-term follow-up results. J Vasc Interv Radiol 2003; 14: 363-7.

12.- Curros F, Chigot V, Emond S, et al: Role of embolisation in the treatment of bronchopulmonary sequestration. Pediatr Radiol. 2000; 30: 769-73.

13.- Ministerio de Salud: Guía Clínica Infección Respiratoria Aguda Baja de manejo ambulatorio en menores de cinco años. 2005.

14.- Castro-Rodríguez J, Holberg C: A Clinical index to define risk of asthma in young children with recurrent wheezing. Am J Respir Crit Care Med. 2000; 162: 1403-6. 